\title{
DOENÇA DO TRATO URINÁRIO EM GATOS (Felis catus domesticus, LINNAEUS, 1758) ATENDIDOS EM CLÍNICAS VETERINÁRIAS DA REGIÃO DE RIBEIRÃO PRETO-SP
}

\author{
NEVES, Letícia ${ }^{1}$ \\ WANDERLEY, Marly Cristina ${ }^{2}$ \\ PAZZINI, Josiane ${ }^{1}$
}

Recebido em: 2010-03-03

Aprovado em: 2011-05-25

ISSUE DOI: $10.3738 / 1982.2278 .571$

\begin{abstract}
RESUMO: O presente estudo teve como objetivos avaliar as afecções e os principais sinais clínicos em felinos domésticos com doença primária ou secundária do trato urinário (DTU) e comparar os sintomas apresentados pelos animais com ou sem obstrução do trato urinário. Foram analisadas 49 fichas de pacientes felinos atendidos em 2 clínicas e 1 hospital veterinário, na região de Ribeirão Preto, SP. Os animais foram separados em grupos de acordo com a existência ou não de obstrução do fluxo urinário e se apresentavam sinais clínicos referentes ao trato urinário secundários a outras doenças. O grupo G1 (animais obstruídos) foi ainda subdividido em confirmados e suspeitos, o G2 (não obstruídos) em confirmados, altamente suspeitos e suspeitos e o G3 foi constituído por felinos com manifestações do trato urinário secundárias à outras afecções. A doença do trato urinário (DTU) foi verificada em 28 (57\%) machos e 21 fêmeas (43\%). O G1 representou 39\% das amostras (19 animais), o G2, 47\% (23 animais) e o G3, 14\% (7 animais). Os sinais clínicos que diferiram entre os grupos G1 e G2 foram: oligúria, bexiga repleta / iscúria, poliúria, presença de plugs e urólitos no G1; piúria, sensibilidade na região renal, aumento de volume abdominal, icterícia, difículdade de locomoção, gengivite e queda de pêlos no G2.
\end{abstract}

Palavras-chave: Doença do trato urinário. Felino. Sinais clínicos. Síndrome urológica felina.

\section{URINARY TRACT DISEASE IN CATS (Felis catus domesticus, LINNAEUS, 1758) CONSULTED IN VETERINARY CLINICS IN THE REGION OF RIBEIRAO PRETO-SP}

\begin{abstract}
SUMMARY: This study aimed to evaluate the afeccion and clinical signs in domestic cats with primary or secondary disease of the urinary tract (DTU), and compare the symptoms shown by animals with or without urinary tract obstruction. It has been analyzed 49 files of feline patients treated in two clinics and one veterinary hospital in the region of Ribeirão Preto, SP. The animals were separated into groups according to whether or not an obstruction of urinary tract was present, and if clinical signs related to the urinary tract were found. The G1 (obstructed animals) was further divided into confirmed and suspected, G2 (non obstructed) in confirmed, suspected and highly suspicious, and G3 was made up of cats with urinary tract manifestations secondary to other diseases. The urinary tract disease (DTU) was seen in being $28(57 \%)$ males and 21 females $(43 \%)$. The G1 accounted for 39\% of samples (19 animals), G2 47\% (23 animals), and G3, 14\% (7 animals). The clinical signs that differed between groups G1 and G2 were: oliguria, full bladder / urinary retention, polyuria, presence of plugs and uroliths in G1; pyuria, renal sensitivity in the region, abdominal swelling, jaundice, locomotion difficulty, gingivitis and falling hairs in G2.
\end{abstract}

Keywords: Urinary tract disease. Feline. Clinical signs. Feline urologic syndrome

\footnotetext{
${ }^{1}$ Acadêmica do Curso de Medicina Veterinária da Faculdade Dr. Francisco Maeda - FAFRAM Ituverava, SP. - leticiaveterinaria@gmail.com; josipazzini@hotmail.com

${ }^{2}$ Docente do Curso de Medicina Veterinária da Faculdade Dr. Francisco Maeda - FAFRAM - Ituverava, SP-marlycwanderley@hotmail.com
} 


\section{INTRODUÇÃO}

O crescente número de felinos na sociedade brasileira e mundial tem inspirado cada vez mais os pesquisadores e clínicos a buscarem informações sobre as doenças e o comportamento destes animais. O número de proprietários conscientes das necessidades dos felinos tem crescido muito, isto demanda maior atendimento nas clínicas veterinárias e obriga o clínico a procurar por mais informações. Apesar da população felina no Brasil ser menor que a de cães, a preferência por gatos tem se tornado uma realidade. Em alguns países a população felina já se tornou maior que a de cães. O reflexo da importância crescente do gato na sociedade é o aumento no número de pós-graduações em medicina felina, simpósios e congressos, centros e clínicas especializadas, medicamentos e dietas específicas para felinos.

As doenças do trato urinário nos felinos têm grande importância, estando entre as principais causas de procura por atendimento na rotina clínica. O trato urinário é um sistema que sofre com as patologias intrínsecas e secundárias.

O rim possui várias funções, principalmente a filtração do sangue para a remoção dos produtos de excreção do metabolismo e o controle de água e eletrólitos que permitem a manutenção do meio interno em equilíbrio químico. Quando há desequilíbrio da homeostase ocorre azotemia (aumento nas concentrações de uréia e creatitina e outras substâncias nitrogenadas não protéicas no sangue), podendo ser de origem pré-renal, renal e pós renal. (NELSON; COUTO, 2001c; GRAUER; DIBARTOLA, 2004).

Sendo o felino um animal extremamente sensível à estas perturbações, sofre com a perda da homeostase, podendo chegar à morte em horas ou dias.

A insuficiência renal aguda (IRA) se desenvolve em horas ou até dias após exposição ao agente agressor. Normalmente ocorre devido hipotensão sistêmica com conseqüente diminuição da perfusão renal, seja por procedimentos que envolvem o uso de anestésicos, como pelo uso de vasodilatadores ou antiinflamatórios não esteroidais (AINE) ou por substâncias potencialmente nefrotóxicas como aminoglicosídeos. Os sinais clínicos geralmente incluem rins aumentados de tamanho ou edemaciados e escore corporal bom. (NELSON; COUTO, 2001b; COWGILL; ELLIOTT, 2004). Na Insuficiência renal crônica (IRC), a lesão no parênquima renal costuma ser irreversível. Ocorre fibrose intersticial devido à deposição de colágeno no local (NELSON; COUTO, 2001b). Os sinais clínicos de IRC incluem polidipsia, poliúria, anemia arregenerativa, rins de formato pequeno e irregular, uremia devido azotemia persistente. Os sinais gastrointestinais como a anorexia, náusea, vômito, acidose, gastrite e também disfagia, devido às ulcerações na mucosa oral, são 
frequentemente notados em pacientes com IRC (NELSON; COUTO, 2001b; POLZIN et al., 2004).

A doença do trato urinário inferior felino (DTUIF) ou Feline lower urinary tract disease (FLUTD) consiste de uma variedade de distúrbios urinários que apresentam sinais clínicos semelhantes. Estes são hematúria, disúria, estrangúria, polaquiúria, periuria, associados ou não à obstrução da uretra (DOREEN, 2007).

Os felinos com inflamação frequentemente apresentam sinais clínicos de polaciúria, hematúria, disúria-estrangúria, obstrução parcial ou completa da uretra, andam de um lado para outro, miam, escondem-se, lambem a genitália e demonstram ansiedade, anorexia, vômito, desidratação, depressão, fraqueza, colapso, torpor, hipotermia, acidose com hiperventilação, bradicardia e até morte súbita, sendo caracterizada como Síndrome urológica felina (NELSON; COUTO, 2001a). Wouters et al.(1998) encontraram, hematúria, disúria e distensão vesical em gatos com síndrome urológica felina. Os principais achados de necropsia e histopatológicos foram cistite hemorrágica, pielonefrite, edema perirrenal, hidronefrose, necrose tubular e uretrite.

Os gatos podem desenvolver cistite por urólitos de estruvita, cristais de estruvita associados ou não a tampões de muco (NELSON; COUTO, 2001a). Os tampões uretrais dos felinos são compostos por mucos associados a minerais ou células epiteliais, hemácias ou leucócitos, o principal mineral é a estruvita (OSBORNE et al., 2004).

A freqüência de infecção bacteriana primária do trato urinário em gatos é baixa devido à formação de urina com alta concentração de uréia e pH baixo que dificultam a colonização do trato urinário por bactérias. Os cristais e os urólitos predispõem à infecção e, no caso da estruvita pode estar associada a excesso de alimento que contenha magnésio e urina alcalina (NELSON; COUTO, 2001a). Segundo Osborne et al.(2004) os tampões uretrais e urólitos estéreis de estruvita são responsáveis por doença do trato urinário inferior em gatos, tanto de natureza obstrutiva como não-obstrutiva.

O felino apresenta uma forma de cistite, com os mesmos sintomas das outras cistites, caracterizada por não se conseguir chegar ao agente específico causador da afecção. Esta forma é conhecida como cistite idiopática ou cistite intersticial felina (OSBORNE et al., 2004) e é a causa mais comum de DTUIF relatada a nível mundial em gatos com idades entre 1-10 anos. As urolitíases constituem a segunda causa de DTUIF (DOREEN, 2007).

Portanto verificar a prevalência das principais afecções do sistema urinário e estudar suas variadas manifestações na rotina clínica constitui-se em importante ferramenta para contribuir efetivamente com uma melhor qualidade de vida do paciente felino com estas 
afecções. Assim, a real situação dos felinos perante esta doença se há diferença entre uma afecção e outra independente das respostas limitadas do trato urinário inferior, precisam ser mais bem estudadas para que o clínico possa chegar a um diagnóstico correto mais facilmente e assim instituir o tratamento adequado.

Esse estudo teve por objetivo relatar as afecções e os principais sinais clínicos apresentados por felinos com doenças primárias ou secundárias do sistema urinário, atendidos em duas clínicas veterinárias e um hospital veterinário, na região de Ribeirão Preto, SP. e ainda comparar os sintomas apresentados pelos animais com ou sem obstrução do trato urinário.

\section{MATERIAL E MÉTODOS}

A pesquisa foi realizada em 2 clínicas veterinárias particulares e 1 hospital veterinário, situados na região de Ribeirão Preto, SP. Foram analisadas 49 fichas de felinos atendidos na rotina clínica com doença do trato urinário. Os dados em relação à quantidade de felinos acometidos, o gênero, a raça e sinais clínicos foram analisados.

Os animais foram separados em grupos de acordo com a existência ou não de obstrução do fluxo urinário e se apresentavam sinais clínicos referentes ao trato urinário secundários à outras afecções, e em seguida, em subgrupos de confirmados, altamente suspeitos e suspeitos. O critério adotado para animais confirmados baseou-se no diagnóstico confirmado na ficha clínica pelo Médico Veterinário que atendeu o animal ou nos sinais clínicos sugestivos da doença confirmados por exames complementares realizados nos mesmos. Para os altamente suspeitos foram considerados os sinais clínicos compatíveis com DTU e exames complementares compatíveis com a doença, porém o resultado do exame é duvidoso por não ser relatada a forma de coleta do material ou não há registro do diagnóstico clínico confirmatório. Já o critério adotado para suspeito foi determinado pelos sinais clínicos compatíveis com DTU, porém o diagnóstico não foi relatado na ficha clínica, nem foram realizados exames complementares que provem o diagnóstico ou o exame realizado não confirma os sinais clínicos.

O Grupo 1 (G1), representa os animais com DTU primária que possuem obstrução do fluxo urinário, sendo distribuídos em dois subgrupos de confirmados e suspeitos. O grupo 2 (G2), representa os animais com DTU primária sem obstrução do fluxo urinário e foram distribuídos em três subgrupos: confirmados, altamente suspeitos e suspeitos. O grupo 3 (G3) foi composto pelos animais que apresentaram manifestações ou alterações no trato urinário, secundariamente a outras causas de base (traumas, afecções em outros sistemas). 


\section{RESULTADOS E DISCUSSÃO}

Foram analisadas 49 fichas de pacientes felinos atendidos em duas clínicas e um hospital veterinário, na região de Ribeirão Preto, SP. Sendo 28 (57\%) machos e 21 fêmeas (43\%). Quanto à raça, os felinos com DTU foram distribuídos de acordo com o Gráfico 1.

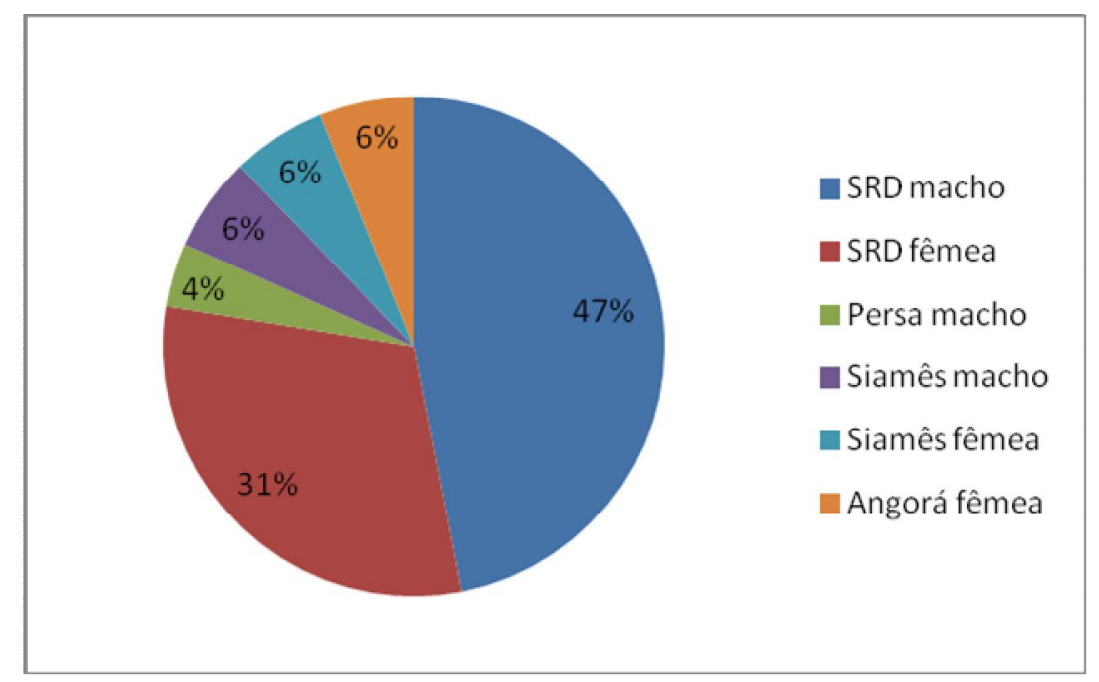

Gráfico 1. Animais com doença do trato urinário distribuídos por sexo e raça.

Conforme demonstrado no gráfico 1, a DTU ocorreu mais em machos do que em fêmeas, porém com uma diferença pequena entre os sexos. Maiores diferenças puderam ser observadas na distribuição entre as raças, sendo que felinos SRD representaram $78 \%$ dos animais acometidos. Entre os animais com raça definida predominaram os siameses (12\%), seguidos pelos da raça Angorá (6\%) e Persa (4\%). Isso concorda com Horta (2006) que cita a predominância de doença do trato urinário em animais SRD seguida pela raça Siamesa. Provavelmente esta distribuição esteja simplesmente refletindo a proporção de animais SRD e não castrados na população da região estudada, que neste caso se caracteriza por apresentar muitos animais de rua e semi-domiciliados, o que aumenta a possibilidade de acasalamento entre animais de diferentes raças.

Os dados a respeito de castração e tipo de alimentação não foram avaliados devido à pequena disponibilidade destas informações. Isto ocorreu, em parte, por desconhecimento dos proprietários, pois alguns animais foram recentemente adotados, outros tinham livre acesso à rua, não sendo possível controlar ou conhecer totalmente suas dietas. Além destes motivos, também foi observada falta de registros adequados de dados em algumas fichas clínicas analisadas. Confer; Panciera (1998), Nelson; Couto (2001d), Brown (2004a) relacionam a dieta e a inflamação como possíveis determinantes na formação de urólitos. A alteração de pH urinário, além de outros fatores, proporcionada pela alimentação e pelas condições 
inflamatórias, influencia a formação de concreções que se depositam em várias partes do trato urinário. A acidez urinária propicia, em geral, a precipitação do oxalato de cálcio, enquanto a alcalinidade, a formação de estruvita.

Nos felinos, em particular, a formação de plugs (compostos formados por muco e minerais) é mais evidente. Os minerais que o compõem são provenientes da dieta. Processos inflamatórios também estão relacionados à formação destes tampões através da deposição de células epiteliais, hemácias ou leucócitos (OSBORNE et al., 2004). Lima et al. (2009) relataram que felinos que recebiam ração seca industrializada de marca popular desenvolveram DTU, sendo esta considerada como o principal agente causador da DTUI nestes animais.

No entanto, em relação à influência da castração sobre a DTU, existem controvérsias. $\mathrm{O}$ animal castrado, em geral, torna-se menos ativo, com tendência à obesidade, diminui a ingestão de água e a frequência em eliminar a urina, predispondo à instalação de DTU (HOWE et al., 2000). Entretanto, Borges et al. [200-?], encontraram que a incidência de urolitíase em animais não castrados foi ligeiramente maior do que nos animais castrados, e dentre estes, os castrados precocemente foram os mais pré-dispostos a esta afecção. Um desenvolvimento menor da uretra ou o aumento da ingestão de comida após a perda da libido são as prováveis causas. Porém, Reche Júnior; Hagiwara; Mamizuka (1998) não encontraram diferença significativa na ocorrência da DTUI entre os animais inteiros e castrados em seu estudo.

Desta forma, apesar da importância em considerar a dieta e a castração na etiologia das afecções urinárias (em particular na dos cálculos), a avaliação, pelo presente trabalho, de quanto estes fatores estão relacionados às doenças do trato urinário de felinos não pode ser realizada.

Os felinos com DTU foram inicialmente separados em 3 grupos, de acordo com a existência ou não de obstrução e a apresentação de sinais clínicos do trato urinário secundário à outras afecções. O grupo dos animais obstruídos (G1) representou 39\% das amostras (19 animais), os não obstruídos (G2) formaram 47\% (23 animais) e os com sintomas urinários como causas secundárias constituíram 14\% (7 animais) (Gráfico 2). 


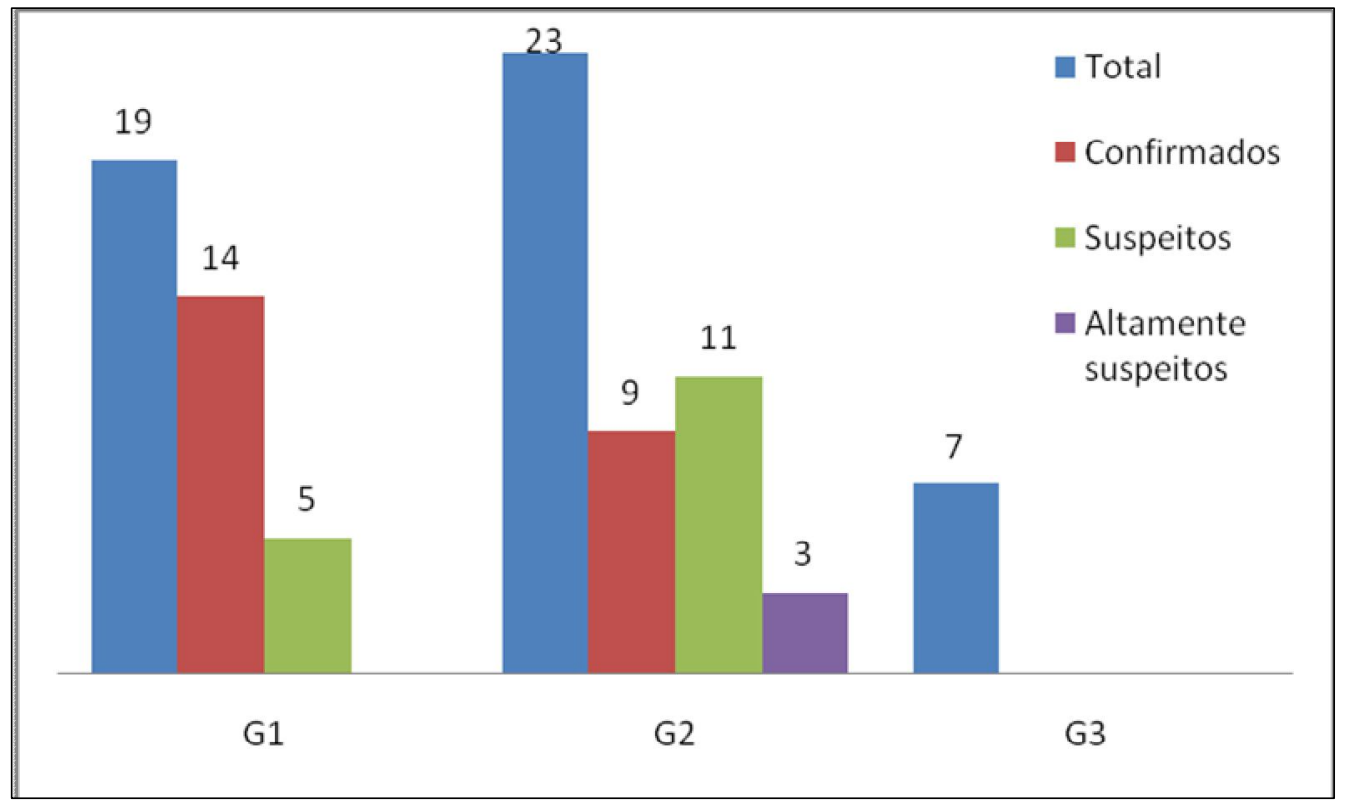

Gráfico 2. Animais com doença do trato urinário distribuídos por grupos e subgrupos. No G1 os animais com DTU primária possuem obstrução do fluxo urinário, sendo distribuídos em dois subgrupos de confirmados e suspeitos. No G2 os animais possuem DTU primária sem obstrução do fluxo urinário e foram distribuídos em três subgrupos: confirmados, altamente suspeitos e suspeitos. O G3 representa os animais com manifestações ou alterações no trato urinário, secundariamente a outras causas de base (traumas, afecções em outros sistemas).

Reche Júnior; Hagiwara; Mamizuka (1998) observaram predominância do grupo de gatos com obstrução urinária sobre os demais grupos estudados em relação à DTU. Estes autores atribuem tal fato ao caráter mais urgente e dramático das manifestações obstrutivas, que levam os proprietários a perceberem a urgência de atendimento profissional. Os demais sintomas, como hematúria e/ou polaquiúria, muitas vezes são subestimados, ou por passarem despercebidos pelos seus proprietários (quando são menos severos), ou devido ao comportamento do gato que quase sempre esconde tanto suas fezes como urina. No entanto, neste trabalho os animais sem obstrução $(\mathrm{G} 2)$ representaram o maior grupo, podendo significar que tem aumentado a atenção dos proprietários aos sinais clínicos manifestados por esta categoria ou simplesmente que a obstrução seja realmente menos frequente entre estes animais do que entre os avaliados pelos referidos autores.

Os dados sobre o número de animais do G1 com DTU distribuídos por afecção e sexo estão listados na tabela 1. 
Tabela 1. Número de animais do G1 com DTU distribuídos por afecção e sexo de um total de 19 animais.

\begin{tabular}{cccc}
\hline Afecção & $\begin{array}{c}\mathbf{N}^{\mathbf{0}} \text { de } \\
\text { animais }\end{array}$ & \multicolumn{2}{c}{$\mathbf{N}^{\mathbf{0}}$ animais } \\
\cline { 3 - 4 } & $(\boldsymbol{\%})$ & $\mathbf{M}$ & $\mathbf{F}$ \\
& & & \\
\hline ITU & $1(5)$ & 1 & \\
IRC & $1(5)$ & & 1 \\
Cistite & $4(21)$ & 3 & 1 \\
Malformação & $1(5)$ & 1 & \\
Urolitíase & $4(21)$ & 4 & \\
ITU/Cistite & $2(11)$ & 2 & \\
IRC/Cistite & $1(5)$ & 1 & \\
IRA/Cistite & $1(5)$ & 1 & \\
Cistite/Urolitíase & $2(11)$ & & 2 \\
Nefrite/Urolitíase & $1(5)$ & & 1 \\
ITU/Cistite/Urolitíase & $1(5)$ & & 1 \\
Total de animais (\%) & $19(100)$ & $13(68)$ & $6(32)$ \\
\hline
\end{tabular}

As afecções com maior prevalência para este grupo foram cistite e urolitíase, ambas apresentadas por $4(21 \%)$ animais, seguidas por ITU/cistite e urolitíase/cistite com $2(11 \%)$ animais cada.

Os animais com obstrução parcial ou total do fluxo urinário mantêm a urina retida por mais tempo, predispondo à formação de urólitos, colonização bacteriana e desenvolvimento de cistite por agressão ao epitélio da vesícula urinária. O felino pode desenvolver cistite principalmente por urólitos de estruvita, cristais de estruvita associados ou não à tampões de muco e urólitos de oxalato de cálcio. Apenas alguns animais apresentam infecção bacteriana primária do trato urinário, pois são, geralmente, os cristais e os urólitos que predispõem à infecção. No caso de cristais de estruvita, sua formação pode estar associada mais a excesso de alimento que contenha magnésio e à urina alcalina do que à infecção (NELSON; COUTO, 2001d). Segundo Osborne et al. (2004), os urólitos estéreis de estruvita e os tampões uretrais de estruvita são os responsáveis por doença do trato urinário inferior em gatos obstruídos e não obstruídos. O felino, particularmente, apresenta alta prevalência de cistite idiopática ou intersticial felina, uma forma de cistite de etiologia indeterminada, que é a causa mais comum de DTUIF relatada em nível mundial em gatos com idades entre 1 e 10 anos. Segundo Doreen (2007), a urolitíase constitui a segunda causa de DTUIF. Entretanto, no presente trabalho, cistite idiopática e urolitíase apareceram em igual número.

O número de machos prevaleceu sobre o de fêmeas. Este dado está em concordância com Lima et al. ( 2009 ) que encontraram maior predisposição à obstrução urinária entre os 
machos, talvez devido à anatomia de sua uretra, que é mais longa e sinuosa (CONFER; PANCIERA, 1998). Reche Júnior; Hagiwara; Mamizuka (1998) relataram em sua pesquisa que todos os felinos com obstrução eram machos, diferente do observado neste trabalho que, embora tenha encontrado maior prevalência de obstrução em machos, também encontrou um número expressivo de fêmeas acometidas. Isto indica que a instalação do processo obstrutivo está ligada a mais fatores que predispõem a formação de tampões e urólitos do que exclusivamente ao diâmetro uretral. Urolitíase foi observada tanto em machos como em fêmeas deste estudo, porém as fêmeas apresentaram outra afecção concomitante.

A cistite e a ITU/cistite foi observada mais em machos, contrariando a literatura que cita fêmeas como mais acometidas por cistite pela proximidade da uretra/vulva com o ânus e por apresentaram quedas de imunidade quando em cio ou paridas, facilitando que bactérias e outros agentes patogênicos colonizem a vesícula urinária (KRUGER et al., 1991; RECHE JUNIOR; HAGIWARA; MAMIZUKA 1998). Porém, estes dados estão de acordo como o estudo realizado por Griffin et al. (1992) citado por Ling (2004) em que a maioria dos gatos com ITU era de machos, o que, em parte pode ser atribuído à passagem de sonda uretral para desobstrução. Nestes casos, a infecção urinária bacteriana não ocorre como causa primária, mas em conseqüência do favorecimento da instalação de microrganismo pela cateterização uretral. Isto pode ser corroborado por Reche Júnior; Hagiwara; Mamizuka (1998) que relataram quatro felinos com DTUI e infecção urinária associadas a procedimentos de cateterizações uretrais anteriores e Horta (2006) que também relacionou DTUI ao uso de cateteres.

Os dados sobre os sinais clínicos apresentados pelos animais do G1 estão listados na tabela 2. 
Tabela 2: Sinais clínicos apresentados pelos animais com DTU dos subgrupos confirmados e suspeitos do G1, distribuídos por afecção de um total de 19 animais.

\begin{tabular}{|c|c|c|c|c|c|c|c|c|c|c|c|c|c|c|}
\hline \multirow{2}{*}{ Sinais clínicos } & \multicolumn{10}{|c|}{ Confirmado $(n=14)$} & \multicolumn{3}{|c|}{ Suspeito $(n=5)$} & \multirow[t]{2}{*}{ Total } \\
\hline & ITU & IRC & Cist & Ur & ITU/Cist & IRC/Cist & IRA/Cist & Cist/Ur & $\mathrm{Nef} / \mathrm{Ur}$ & ITU/Cist/Ur & Cist & $\mathrm{MF}$ & $\mathrm{Ur}$ & \\
\hline $\mathrm{N}^{\circ}$ animais & 1 & 1 & 2 & 2 & 2 & 1 & 1 & 2 & 1 & 1 & 2 & 1 & 2 & 19 \\
\hline Disúria & 1 & 1 & 1 & 2 & & 1 & & & 1 & 1 & 2 & & 1 & 11 \\
\hline Hematúria & 1 & & 1 & 1 & & & 1 & 2 & 1 & 1 & 1 & 1 & & 10 \\
\hline Oligúria & & 1 & & & & & & & & & 1 & & 1 & 3 \\
\hline Estrangúria & & & & & 2 & 1 & & & & & & 1 & 1 & 5 \\
\hline Anúria/ Bexiga vazia & & & 1 & & 1 & 1 & 1 & & 1 & & & 1 & 1 & 7 \\
\hline Bexiga repleta / iscúria & 1 & & 1 & & 1 & 1 & & & & & & & & 4 \\
\hline Enurese & & & & & & & & & & 1 & & & & 1 \\
\hline Polaquiúria & & & & & & 1 & & & & & & & & 1 \\
\hline Poliúria & & & & & & & & & & & 1 & & & 1 \\
\hline Plugs & & & & & & & 1 & & & & & & & 1 \\
\hline Urólito & & & & 1 & & & & & & 1 & & & & 2 \\
\hline Sensibilidade abdominal & & 1 & & & 1 & 1 & & & & & & & & 3 \\
\hline Emese & & & & & & 1 & & & & & & & & 1 \\
\hline Polidpisia & & & & & & & & & & & 1 & & & 1 \\
\hline Desidratação & & & & & & 1 & & & & & & & & 1 \\
\hline Depressão/apatia & & & 2 & & & 1 & 1 & & & & & & 1 & 5 \\
\hline Hipotermia & 1 & & & & & 1 & & & & & & & & 2 \\
\hline Hipertermia & & & & & & & & & & & 1 & & & 1 \\
\hline Disquesia/Constipação & & & & 1 & 1 & & & & & & & & & 2 \\
\hline Fecaloma & & & & & & 1 & & & & & & & & 1 \\
\hline
\end{tabular}

Cist: Cistite; Ur: Urolitíase; Nef: Nefrite; MF: Mal formação 
Todos estes sinais clínicos são compatíveis com animais obstruídos, que podem apresentar concomitantemente infecção, inflamação e urólitos. Disúria, estrangúria, anúria e vesícula repleta são sinais de obstrução. Em obstruções ureterais a vesícula pode ficar vazia, e o acúmulo de urina nas estruturas do trato urinário superior pode causar hidronefrose. De acordo com Confer; Panciera, (1998) as obstruções do trato urinário inferior também acabam acometendo o trato superior, pois determinam o aumento da pressão intratubular resultando em dilatação dos túbulos renais e compressão do parênquima renal. A depressão observada nos animais obstruídos é devida à azotemia pós-renal. A retenção da urina permite o acúmulo de uréia e creatinina que promovem seus efeitos tóxicos. A hipercalemia e uremia são as maiores causas de mortes em gatos com obstrução. Os animais que apresentam muitas recidivas desenvolvem em longo prazo insuficiência renal crônica ou insuficiência renal secundária à pielonefrite ascendente, especialmente se foram feitas cateterizações repetidas da uretra (NELSON; COUTO, 2001d).

Wouters et al. (1998) citam obstrução uretral, hematúria, disúria e distensão vesical como os sinais mais encontrados em gatos com síndrome urológica felina. Nelson; Couto (2001a) afirmaram que o achado mais significativo em gatos com obstrução é a vesícula urinária túrgida e distendida, enquanto no presente trabalho o principal sinal observado nos gatos obstruídos foi a disúria.

Os principais sinais clínicos encontrados por Horta (2006) em animais obstruídos foram disúria, anorexia, apatia, vocalização, oligodipsia, desidratação, taquipnéia e hipotermia, o que difere em parte do presente estudo, que encontrou como principal manifestação disúria, hematúria, anúria/bexiga vazia, estrangúria e depressão, bexiga repleta/iscúria.

$\mathrm{Na}$ inflamação do trato urinário inferior a vesícula urinária é a mais acometida, as outras estruturas geralmente inflamam associadas à vesícula e não como causa primária. $\mathrm{Na}$ cistite aguda ocorrem hemorragias, úlceras, parede espessada devido a edema e infiltração de células inflamatórias e difusa ou focalmente hemorrágicas (CONFER; PANCIERA, 1998).

Segundo Ling (2004) os sinais em cães são polaciúria, hematúria, urina fétida, e mais raramente, febre e evidência de dor abdominal. Porém muitos animais nem apresentam sinais clínicos. A ITU é, em geral, rara em felinos jovens com a prevalência aumentando com a idade. Geralmente é mais um fator secundário do que etiológico primário, como, por exemplo, nas obstruções onde as defesas naturais estão comprometidas (OSBORNE et al., 2004).

Todos os animais analisados desenvolveram sinais clínicos compatíveis com a literatura, com algumas manifestações além do comum, por exemplo, a disquesia/constipação, 
porém todas se relacionam com a obstrução e com azotemia/uremia causada pela obstrução e pela falência renal.

Em estudo realizado por Camargo et al. (2009), um felino que apresentou cistite crônica com obstrução desenvolveu os sinais clínicos de prostração, anorexia, disúria, polaquiúria e hematúria. Esses sinais são compatíveis com o presente estudo.

Segundo a literatura os sinais clínicos de IRC incluem polidipsia, poliúria, anemia arregenerativa, rins de formato pequeno e irregular, uremia devido azotemia persistente. Os sinais gastrointestinais como a anorexia, náusea, vômito, acidose, gastrite e também disfagia, devido às ulcerações na mucosa oral, são frequentemente notados em pacientes com IRC (NELSON; COUTO, 2001b; POLZIN et al.,2004).

Os sinais clínicos apresentados pelos pacientes com IRA geralmente incluem rins aumentados de tamanho ou edemaciados e escore corporal bom, depressão principalmente se o paciente apresentar sinais de oligúria e azotemia (NELSON; COUTO, 2001b; COWGILL; ELLIOTT, 2004). A IRA pós-renal indica obstrução no trato urinário inferior (TUI) ou desvio do fluxo urinário e o conseqüente acúmulo de metabólitos, que deveriam ser excretados, no organismo. A etiologia da IRA pós-renal envolve obstrução de ureter, bexiga e uretra, completa ou parcial, por urólitos, tampões mucosos, coágulos de sangue ou massas intra ou extraluminais. A obstrução por urólitos de oxalato vem sendo identificada com freqüência cada vez maior como causa de azotemia pós-renal em gatos, causando oligúria e uremia. (COWGILL; ELLIOTT, 2004; ELLIOTT, 2008; ROSS, 2008). Em cães e gatos com hematúria causada por inflamação, traumatismo ou neoplasia, os sinais clínicos concomitantes quase sempre incluem polaciúria, disúria e estrangúria, e isso aconteceu em vários animais analisados.

Os urólitos podem lesar o epitélio do trato urinário causando inflamação e infecção e o animal demonstra sinais de hematúria, polaciúria, disúria-estrangúria e quando obstrui o fluxo urinário o animal desenvolve azotemia (depressão, anorexia e vômito) (NELSON; COUTO, 2001d).

Os felinos com inflamação frequentemente apresentam sinais clínicos de polaciúria, hematúria, disúria-estrangúria, obstrução parcial ou completa da uretra, andam de um lado para outro, miam, escondem-se, lambem a genitália e demonstram ansiedade, anorexia, vômito, desidratação, depressão, fraqueza, colapso, torpor, hipotermia, acidose com hiperventilação, bradicardia e até morte súbita. Sendo caracterizada como Síndrome urológica felina (NELSON; COUTO, 2001c).

Os dados sobre o número de animais do G2 com DTU distribuídos por afecção e sexo 
estão listados na tabela 3.

Tabela 3. Número de animais do G2 com DTU distribuídos por afecção e sexo de um total de 23 animais.

\begin{tabular}{c|c|c|c}
\hline & $\mathbf{N}^{\mathbf{0}}$ de & \multicolumn{2}{c}{$\mathbf{N}^{\mathbf{o}}$ de animais } \\
\cline { 3 - 4 } Afecção & animais & $\mathbf{M}$ & $\mathbf{F}$ \\
\hline ITU & $1(4)$ & 1 & \\
IRA & $5(22)$ & 3 & 2 \\
IRC & $1(4)$ & & 1 \\
Cistite & $3(13)$ & & 3 \\
ITU/cistite & $5(22)$ & 1 & 4 \\
ITU/nefrite & $1(4)$ & & 1 \\
Cistite/nefrite & $1(4)$ & 1 & \\
ITU/IRA/cistite & $3(13)$ & 2 & 1 \\
IRA/cistite/nefrite & $1(4)$ & 1 & \\
IRC/nefrite & $1(4)$ & 1 & \\
ITU/IRA/cistite/nefrite & $1(4)$ & 1 & \\
Total de animais (\%) & $23(100)$ & $11(48)$ & $12(52)$ \\
\hline
\end{tabular}

As afecções com maior prevalência foram IRA e ITU/cistite, ambas representadas por $5(23 \%)$ animais, seguidas por cistite e ITU/IRA/cistite com 3 (13\%) animais cada.

Isso difere do que ocorreu aos obstruídos, em que a urolitíase esteve presente de forma isolada ou associada à infecção e inflamação do trato urinário. Isso reforça a importância da urolitíase como fator predisponente à infecção e inflamação do TU e a retenção da urina que contribui para a formação de urólitos e crescimento bacteriano. Nesse grupo qualquer segmento do TU pode ser acometido igualmente, talvez por isso a IRA tenha aparecido em igual número a infecção e inflamação do TUI.

Entre os felinos que não apresentaram obstrução, 11 (48\%) eram machos e 12 (52\%) fêmeas. Esse achado também difere dos animais obstruídos, em que os machos foram os que prevaleceram. A hipótese de que a obstrução acomete mais os machos porque a uretra é longa e sinuosa pode ter influenciado o número de machos ser mais elevado no G1.

O número de fêmeas com ITU/cistite e cistite foi maior que o de machos. O fato das fêmeas terem sido mais acometidas pela infecção seguida por inflamação do TUI pode ser explicado pela proximidade da uretra e vulva ao ânus e pela queda de imunidade em cios ou gestações. Este achado está de acordo com o citado pela literatura com relação à maior prevalência de cistite bacteriana em fêmeas devido ao menor comprimento uretral e à maior proximidade da abertura da uretra com o ânus (KRUGER et al., 1991; RECHE JUNIOR; HAGIWARA; MAMIZUKA, 1998). 
Os dados sobre os sinais clínicos apresentados pelos animais do G2 estão listados na tabela 4 e tabela 5 .

Tabela 4. Sinais clínicos apresentados pelos animais com DTU do subgrupo confirmados do G2, distribuídos por afecção de um total de 8 animais.

\begin{tabular}{|c|c|c|c|c|c|c|c|c|}
\hline \multirow[b]{2}{*}{ Sinais clínicos } & \multicolumn{8}{|c|}{ Confirmado $(n=8)$} \\
\hline & ITU & IRA & IRC & Cist & $\begin{array}{l}\text { ITU } \\
\text { Cist }\end{array}$ & $\begin{array}{l}\text { ITU } \\
\text { IRA } \\
\text { Cist }\end{array}$ & $\begin{array}{l}\text { IRA } \\
\text { Cist } \\
\text { Nef }\end{array}$ & $\begin{array}{l}\text { ITU } \\
\text { IRA } \\
\text { Cist } \\
\text { Nef }\end{array}$ \\
\hline $\mathrm{N}^{\mathrm{o}}$ animais & 1 & 1 & 1 & 1 & 1 & 1 & 1 & 1 \\
\hline Disúria & & & & 1 & & 1 & & \\
\hline Hematúria & & & & 1 & 1 & 1 & 1 & 1 \\
\hline Estrangúria & & & & & & 1 & & \\
\hline Anúria/ Bexiga vazia & & & & 1 & & 1 & & \\
\hline Enurese & & & & & & 1 & & \\
\hline Polaquiúria & & & & & & 1 & & \\
\hline Piúria & & & & & & 1 & & \\
\hline Sensibilidade abdominal & & & & & & & & \\
\hline Sensibilidade região renal & & & & & & & 1 & \\
\hline Aumento de volume abdominal & & & & & & 1 & & \\
\hline Emese & & & & & & & 1 & \\
\hline Polidipsia & & & & & & & & \\
\hline Desidratação & & & & & & & & \\
\hline Depressão/Apatia & 1 & 1 & & & 1 & 1 & 1 & \\
\hline Hipotermia & & & & & & 1 & 1 & \\
\hline Hipertermia & & & & & 1 & & & \\
\hline Icterícia & 1 & & & & & & & \\
\hline Dificuldade de locomoção & & & & & & 1 & & 1 \\
\hline Gengivite & & & 1 & & & & 1 & \\
\hline Disquesia/Constipação & & & & & & & & \\
\hline
\end{tabular}

Cist: Cistite; Nef: Nefrite 
Tabela 5. Sinais clínicos apresentados pelos animais com DTU dos subgrupos altamente suspeitos e suspeitos do G2, distribuídos por afecção de um total de 13 animais.

Cist: Cistite; Nef: Nefrite;

\begin{tabular}{|c|c|c|c|c|c|c|c|c|c|}
\hline \multirow{2}{*}{ Sinais clínicos } & \multicolumn{2}{|c|}{$\begin{array}{c}\text { Altamente } \\
\text { suspeito }(n=3)\end{array}$} & \multicolumn{7}{|c|}{ Suspeito $(n=10)$} \\
\hline & $\begin{array}{l}\text { ITU } \\
\text { Cist }\end{array}$ & $\begin{array}{c}\text { ITU/IRA } \\
\text { Cist } \\
\end{array}$ & IRA & Cist & $\begin{array}{l}\text { ITU } \\
\text { Cist }\end{array}$ & $\begin{array}{l}\text { ITU } \\
\text { Nef }\end{array}$ & $\begin{array}{l}\text { Cist } \\
\text { Nef }\end{array}$ & $\begin{array}{c}\text { ITU/IRA } \\
\text { Cist }\end{array}$ & IRC/Nef \\
\hline $\mathrm{N}^{\mathrm{o}}$ animais & 2 & 1 & 4 & 1 & 1 & 1 & 1 & 1 & 1 \\
\hline Disúria & & 1 & & & & & & 1 & \\
\hline Hematúria & 2 & & & 1 & & & 1 & 1 & \\
\hline Estrangúria & & 1 & & & 1 & & & & \\
\hline $\begin{array}{c}\text { Anúria/ Bexiga } \\
\text { vazia }\end{array}$ & 1 & & 1 & & & & & & \\
\hline Polaquiúria & & & & 1 & & & & & \\
\hline $\begin{array}{l}\text { Sensibilidade } \\
\text { abdominal }\end{array}$ & & & & 1 & & & & & \\
\hline $\begin{array}{l}\text { Sensibilidade } \\
\text { região renal }\end{array}$ & & & & & & 1 & 1 & & \\
\hline Emese & & 1 & 1 & & & & & & 1 \\
\hline Polidipsia & & 1 & & & & & 1 & & \\
\hline Desidratação & & & 1 & & & & & & 1 \\
\hline Depressão/Apatia & 1 & & 2 & & & 1 & & & 1 \\
\hline Hipotermia & & & 1 & & & & & & 1 \\
\hline Hipertermia & & & & & & 1 & & & \\
\hline Gengivite & & & 1 & & & & & & \\
\hline $\begin{array}{l}\text { Disquesia/ } \\
\text { Constipação }\end{array}$ & & & 1 & & & & & & \\
\hline Fecaloma & & & 1 & & & & & & \\
\hline Queda de pelo & & & 1 & & & & & & \\
\hline
\end{tabular}

Considerando-se todas as afecções clínicas apresentadas, os principais sinais clínicos foram por ordem de importância: hematúria e depressão/apatia com 10 animais (48\%) cada; disúria, anúria/bexiga vazia, êmese e hipotermia 4 (19\%) animais cada; estrangúria, sensibilidade na região renal e gengivite com 3 (14\%) cada; polaquiúria, polodipsia, hipertermia, dificuldade de locomoção e, desidratação com 2 (10\%) animais cada uma; enurese, piúria, sensibilidade abdominal, aumento de volume abdominal, iciterícia, disquesia/constipação, fecaloma e queda de pêlo com 1 (5\%) animal cada

Essa ordem de importância foi diferente dos sinais clínicos apresentados pelos animais do G1, onde a disúria foi a sintomatologia mais importante. Os sinais clínicos que diferiram entre os grupos G1 e G2 foram o aparecimento de oligúria, bexiga repleta/iscúria, poliúria, presença de plugs e urólitos no G1; piúria, sensibilidade na região renal, aumento de volume abdominal, icterícia, dificuldade de locomoção, gengivite e queda de pêlos no G2. A vesícula urinária repleta é referida por Nelson; Couto (2001c) como o achado mais significativo em 
um gato com obstrução, isso concordou em parte com o presente trabalho e já foi discutida esta discordância. Os plugs e os urólitos são dois fatores causadores de obstrução, reforçando aqui a sua participação nessa afecção.

Os sinais clínicos apresentados pelos animais estão de acordo com a literatura e a maior parte já foi discutida anteriormente. Alguns sinais clínicos não específicos do TU como, por exemplo, icterícia, gengivite, disquesia e fecaloma são decorrentes de outras afecções sistêmicas que estão ocorrendo concomitantemente.

Segundo Nelson; Couto (2001c), o felino com DTUI mostra-se aparentemente sadio ao exame físico quando não ocorrem simultaneamente à outras afecções do trato urinário ou sistêmicas. A vesícula urinária está pequena e fácil de ser comprimida, sua parede pode estar espessada, e a palpação pode fazer o animal urinar. A manipulação do abdome caudal pode ser dolorosa (sensibilidade abdominal). $\mathrm{O}$ animal pode não reagir à manipulação quando gravemente deprimido ou comatoso. Para Osborne et al. (2004) as DTUI idiopáticas não obstrutivas apresentam os sinais clínicos de periúria, estrangúria e hematúria mais comumente, e muitas vezes precedem a forma obstrutiva.

No G3 os dados sobre o número de animais com DTU distribuídos por afecção e sexo estão listados na tabela 6

Tabela 6. Número de animais do G3 com DTU secundária a outras afecções distribuídos por afecção e sexo de um total de 7 animais.

\begin{tabular}{c|c|c|c}
\hline \multirow{2}{*}{ Afecção } & \multirow{2}{*}{$\begin{array}{c}\text { No de } \\
\text { animais }\end{array}$} & \multicolumn{2}{|c}{\begin{tabular}{c}
\multicolumn{2}{c}{ ande } \\
animais
\end{tabular}} \\
\cline { 3 - 4 } & & $\mathbf{M}$ & $\mathbf{F}$ \\
\hline DTU & 7 & 4 & 3 \\
Total de animais (\%) & $7(100)$ & $4(57)$ & $3(43)$ \\
\hline
\end{tabular}

Os principais sinais clínicos foram em ordem de importância: hematúria, depressão e hipotermia, disúria, iscúria/aumento volume da bexiga, estrangúria, anúria/bexiga vazia, emese, hipertermia, anorexia, dificuldade de locomoção, sensibilidade região renal, rim aumentado de volume, fratura de bacia e fêmur, úlceras dérmicas, disquesia/constipação, fecaloma. (Tabela 7). 
Tabela 7: Sinais clínicos apresentados pelos animais do G3 de um total de 7 animais

\begin{tabular}{cc}
\hline Sinais clínicos & G3 (n=7) \\
\cline { 2 - 2 } Disúria & 7 \\
\hline Iscúria/ aumento volume da bexiga & 1 \\
Hematúria & 4 \\
Estrangúria & 1 \\
Anúria/ Bexiga vazia & 1 \\
Emese & 1 \\
Depressão & 3 \\
Hipotermia & 2 \\
Hipertermia & 1 \\
Anorexia & 1 \\
Dificuldade de locomoção & 1 \\
Sensibilidade região renal & 1 \\
Rim aumentado de volume & 1 \\
Fratura de bacia e fêmur & 1 \\
Úlceras dérmicas & 1 \\
Disquesia/Constipação & 1 \\
Fecaloma & 1 \\
\hline
\end{tabular}

Esses animais manifestaram sinais clínicos secundários a outras afecções primárias, isso demonstra o quanto o trato urinário é sensível e responsível aos outros sistemas. Segundo Osborne et al. (2004) os traumas que lesam a região lombosacral podem causar disfunção do neurônio motor inferior. Isso faz com que o animal retenha a urina, ou provoque incontinência, e até paralisia completa da bexiga, da uretra, do reto e da cauda. Transtornos traumáticos renais ocorrem geralmente em acidentes automobilísticos, lesando os vasos sanguíneos produzindo hemorragia e até alterar a função tubular. $\mathrm{O}$ animal pode apresentar hematúria intensa, chegando ao estado de hipovolemia. Dor na região lombar, e rins aumentados de tamanho, urina na cavidade abdominal também podem estar presentes (BROWN, 2004b). Outras causas infecciosas como na peritonite infecciosa felina não efusiva (PIF) os rins estão aumentados e dolorosos. (FRANCEY; SCHWEIGHAUSER, 2008).

Isso explica muitos sinais clínicos apresentados pelos animais como constipação, disúria, hematúria, sensibilidade renal etc.

Os estudos retrospectivos de casos clínicos fornecem dados da real situação dos animais no atendimento de rotina veterinária (LIMA et al., 2007; SILVA et al., 2008; SILVA et al., 2009). Porém, esse tipo de estudo fica na dependência de informações contidas nas fichas clínicas dos pacientes. Foi o que aconteceu com o presente trabalho em que as 
conclusões foram baseadas em registros relatados na rotina clínica. Isso pode conduzir à super ou a subestimação de dados.

\section{CONCLUSÃO}

Os três grupos de animais estudados apresentaram diferenças quanto aos sintomas exibidos. As principais alterações encontradas entre os animais com fluxo urinário obstruído (G1) foram a presença de cistite, urolitíase e infecção. Os machos foram mais acometidos que as fêmeas, provavelmente devido ao fato de apresentarem uma uretra longa e sinuosa que favorece a oclusão da luz uretral por urólitos e plugs. As manifestações clínicas apresentadas pelos animais deste grupo podem ser atribuídas à retenção urinária, à formação de plugs e urólitos e também aos procedimentos utilizados para a desobstrução.

O grupo de animais com DTU, mas sem obstrução do fluxo urinário (G2) foi constituído predominantemente por fêmeas, uma vez que estas estão menos propensas às causas de obstrução. As afecções predominantes neste grupo foram IRA, cistite e infecção. Nesses animais qualquer região do trato urinário pode ser acometida igualmente. Como as causas de obstrução são menos freqüentes em fêmeas, inflamação e infecção aparecem em maior proporção. Os sinais clínicos apresentados por estes animais estão relacionadas às doenças do trato urinário associadas à outras afecções sistêmicas.

O grupo constituído por animais com doenças do trato urinário secundárias à outras afecções sistêmicas (G3) apresentou como principais sintomas hematúria, depressão e hipotermia. A presença de sinais clínicos relacionados ao trato urinário em animais apresentando outras doenças de base permite concluir que o trato urinário é sensível à outras afecções e responde às injúrias sistêmicas, mesmo que de forma secundária.

Os sinais clínicos que diferiram entre os grupos G1 e G2 neste estudo foram

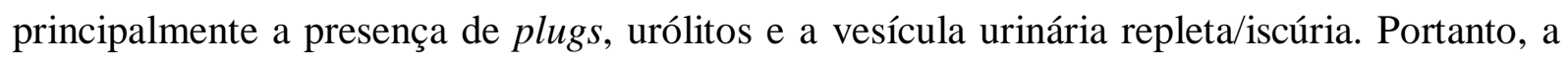
presença desses fatores pode direcionar o clínico ao diagnóstico de obstrução ou não do trato urinário.

A falta de registros adequados nas fichas clínicas impediu a análise de dados importantes que interferem no trato urinário. Isso demonstra falta de padronização nos relatos e muitas vezes descaso por parte dos Médicos Veterinários que realizam o atendimento desses animais, dificultando a realização de estudos, o que prejudica a evolução científica e literária da Medicina Veterinária.

Sugerimos uma melhor abordagem destes pacientes, principalmente em relação ao registro de informações em suas fichas clínicas, bem como a conscientização dos proprietários 
sobre a necessidade de realização de exames complementares, que são importantes ferramentas para uma conduta clínica eficaz.

A atualização constante de dados epidemiológicos relativos às doenças que acometem o trato urinário de felinos contribui de maneira efetiva, não apenas como um diagnóstico de situação, mas para o embasamento de protocolos terapêuticos. Desta maneira novos trabalhos devem ser realizados para dar continuidade ao propósito que iniciamos de caracterizar as doenças do trato urinário entre os pacientes felinos atendidos na rotina clínica veterinária.

\section{REFERÊNCIAS}

BORGES, T. M. et al. Incidência de casos de urolitiase em felinos no município de Imperatriz-ma. In: SICA,9., 200?, Anais eletrônicos...

aBROWN, S. A. Enfermedades Del riñón: Nefrolitos. In: MORGAN, R. V; BRIGHT, R. M.; SWARTOUT, M. S. Clínica de pequeños animals. 4. ed. Madrid: Elsevier España , 2004. p. $523-524$.

bBROWN, S. A. Enfermedades Del riñón: Transtornos traumáticos. In: MORGAN, R. V; BRIGHT, R. M.; SWARTOUT, M. S. Clínica de pequeños animals. 4. Ed. Madrid: Elsevier España , 2004. p. 525 - 526.

CAMARGO, N. I. et al. Cistite crônica em gato da raça maine coon: relato de caso. Disponível em: <http://www.eventosufrpe.com.br/jepex2009/cd/resumos/R0643-4.pdf>. Acesso em : 15 nov. 2010.

CONFER, A. W. ; PANCIERA, R. J. Sistema urinário. In: CARLTON, W. W; McGAVIN, M. D. Patologia veterinária especial de thomson. 2.ed. Porto Alegre: Tecmedd, 1998. p. 228-265.

COWGILL, L. D.; ELLIOTT, D. A. Insuficiência renal aguda. In: ETTINGER, S.J.; FELDMAN, E. C.Tratado de medicina interna veterinária: doenças do cão e gato. 5.ed. Rio de Janeiro: Guanabara Koogan, 2004. v.1. p. 1701-1721.

DOREEN, M. H. Epidemiologia da urolitíase felina. Veterinary Focus, v. 17, n. 1, 2007

ELLIOTT, J. O gato azotêmico. Veterinary Focus, v.18, n.2. p. 8-15. Jun. 2008.

FRANCEY, T.; SCHWEIGHAUSER, A. Epidemiologia clínica das doenças renais no gato. Veterinary Focus, v.18, n.2. p. 2 - 7. Jun. 2008.

GRAUER, G. F.; DIBARTOLA, S. P. Doença Glomerular. In: ETTINGER, S.J.; FELDMAN, E. C.Tratado de medicina interna veterinária: doenças do cão e gato. 5.ed. Rio de Janeiro: Guanabara Koogan, 2004. v.2. p. 1751 - 1768. 
GRIFFIN, D. W., et al. Prevalence of bacterial urinary tract infection after perineal urethrostomy in cats. JAVMA. 200:681, 1992. In: LING, G. V. Infecções bacterianas do trato urinário. In: ETTINGER, S.J.; FELDMAN, E. C.Tratado de medicina interna veterinária: doenças do cão e gato. 5.ed. Rio de Janeiro: Guanabara Koogan, 2004. v.2. p. 1769 - 1776.

HORTA, P. V. P. Alterações clínicas, laboratoriais e eletrocardiográficas em gatos com obstrução uretral. 2006. 87 f. Dissertação (Mestrado em Medicina Veterinária) - Faculdade de Medicina Veterinária e Zootecnia, Universidade de São Paulo.

HOWE, L.M. et al. Long-term outcome of gonadectomy performed at an early age or traditional age in cats. Journal of the American Veterinary Medical Association., v. 217, n.11, p. 1661-1665, 2000.

KRUGER, J. M. et al. Clinical evaluation of cats with lower urinary tract disease. J. Am. Vet. Med. Assoc. 199,211-216, 1991.

LIMA, E. R. et al. Avaliação das concentrações séricas dos minerais, proteínas, enzimas e urinálise em gatos domésticos com Doença do Trato Urinário Inferior. Medicina Veterinária v.3, n.1, p.1-10, 2009

LIMA, E.R. et al. Doença do trato urinário inferior em gatos domésticos (Felis domesticus, Linnaeus, 1758), atendidos no hospital veterinário da universidade federal rural de pernambuco. Ciênc. vet. tróp. v. 10, n. 2/3, p. 113 - 118, 2007

LING, G. V. Infecções bacterianas do trato urinário. In: ETTINGER, S.J.; FELDMAN, E. C.Tratado de medicina interna veterinária: doenças do cão e gato. 5.ed. Rio de Janeiro: Guanabara Koogan, 2004. v.2. p. 1769 - 1776.

aNELSON, R. W.; COUTO, C. G. Inflamação do trato urinário inferior dos felinos. In: NELSON, Richard W.; COUTO, C. Guillermo. Medicina interna de pequenos animais. 2.ed.. Rio de Janeiro: Guanabara Koogan, 2001. p. 517-522.

bNELSON, R. W.; COUTO, C. G. Insuficiência renal. In: NELSON, Richard W.; COUTO, C. Guillermo. Medicina interna de pequenos animais. 2.ed.. Rio de Janeiro: Guanabara Koogan, 2001. p.487-499.

cNELSON, R. W.; COUTO, C. G.. Manifestações clínicas dos distúrbios urinários. In: NELSON, Richard W.; COUTO, C. Guillermo. Medicina interna de pequenos animais. 2.ed.. Rio de Janeiro: Guanabara Koogan, 2001. p.454-531.

dNELSON, R. W.; COUTO, C. G. Urolitíase canina. In: NELSON, Richard W.; COUTO, C. Guillermo. Medicina interna de pequenos animais. 2.ed.. Rio de Janeiro: Guanabara Koogan, 2001. p. 506 - 515.

OSBORNE, C. A. et al.. Doença do trato urinário inferior dos felinos. In: ETTINGER, S.J.; FELDMAN, E. C. Tratado de medicina interna veterinária: doenças do cão e gato. 5.ed. Rio de Janeiro: Guanabara Koogan, 2004. v.1. p. 1802-1841. 
POLZIN, D. J. et al. Insuficiência renal crônica. In: ETTINGER, S.J.; FELDMAN, E. C.Tratado de medicina interna veterinária: doenças do cão e gato. 5.ed. Rio de Janeiro: Guanabara Koogan, 2004. v.1. p. 1721-1751.

RECHE JUNIOR. A; HAGIWARA M. K;MAMIZUKA, E. Estudo clínico da doença do trato urinário inferior em gatos domésticos de São Paulo. Braz. J. Vet. Res. Anim. Sci., v. 35, n. 2 , p. 69-74, 1998.

RECHE JUNIOR, A. A orbifloxacina no tratamento das cistites bacterianas em gatos domésticos. Ciência Rural, v.35, n.6, p. 1325- 1330, 2005.

ROSS, S. A uremia aguda no gato. Veterinary Focus. v.18, n. 2, p. 31 - 38, 2008.

SILVA, C. C. da, et al. Casuística de felinos com DTUIF atendidos no hospital de Clínicas veterinária da universidade federal de pelotas (HCVUFPEL) no período de janeiro de 2004 até dezembro de 2008. In: Congresso de iniciação científica, 17; Encontro de Pós-graduação, 10., 11-14 nov. 2008, Pelotas. Anais eletrônicos... Disponível em: <

http://www.ufpel.edu.br/cic/2008/cd/pages/pdf/CA/CA_01829.pdf>. Acesso em: 28 set. 2009.

SILVA, G.O. et al. Doenças do trato urinário: perfil nosológico dos atendimentos a cães e gatos em um hospital universitário. In: Congresso brasileiro de medicina veterinária, 35., 1922 out. 2008, Gramado. Anais eletônicos... Disponível em: < http://www.sovergs.com.br/conbravet2008/anais/cd/resumos/R0093-2.pdf>. Acesso em: 28 set. 2009.

WOUTERS, F. et al. Síndrome urológica felina: 13 casos. Ciência Rural. v. 28, n. 3, p. 497 500, 1998. 
